\title{
Intoxicação estafilocócica em restaurante institucional
}

\author{
Staphylococcal intoxication in a institutional restaurant
}

\author{
Kelly Lameiro Rodrigues ${ }^{1}$ Angela Nunes Moreira ${ }^{2}$ Angela Terezinha Santiago Almeida ${ }^{3}$ \\ Daiane Chiochetta $^{4}$ Maria Joana Rodrigues ${ }^{5}$ Claudiomar Soares Brod $^{6}$ \\ José Beiro Carvalhal ${ }^{7}$ José Antonio Guimarães Aleixo ${ }^{8}$
} \begin{abstract}
Foi investigado um surto de intoxicação
alimentar ocorrido em um restaurante institucional. RESUMO Cinqüenta e seis pessoas, de um total de 88, foram acometidas de vômitos, diarréia, dores abdominais, prostração, febre e cefaléia após ingerirem uma refeição composta de sanduíche de galinha, refresco de laranja e pudim de leite. Os sintomas apareceram entre uma hora e meia e 12 horas após a ingestão da refeição e duraram 24 a 36 horas. As taxas de ataque específico foram de $64 \%$ para o sanduíche de galinha, de $61 \%$ para o refresco de laranja e de $60 \%$ para o pudim. A contagem de Staphylococcus aureus secretores de enterotoxina A no sanduíche de galinha foi de $2 \times 10^{8} \mathrm{UFC} . \mathrm{g}^{-1}$. Estes resultados, juntamente com os obtidos nos questionários aplicados às pessoas que ficaram doentes, forneceram provas circunstanciais que permitiram concluir que ocorreu uma intoxicação alimentar provocada pelo sanduíche de galinha contaminado com enterotoxina A de Staphylococcus aureus.
\end{abstract}

Palavras-chave: intoxicação alimentar, Staphylococcus aureus, enterotoxina $A$.

\section{ABSTRACT}

An outbreak of foodbome intoxication in an institutional restaurant was investigated. Fifty-six people, out of 88, had vomiting, diarrhea, abdominal pain, prostration, fever and headache after eating a meal that included chicken sandwich, orange drink and milk pudding. Symptoms appeared between one and a halfhour and 12 hours after eating the meal and lasted from 24 to 36 hours. Specific attack rates were $64 \%$ for chicken sandwich, $61 \%$ for orange drink and $60 \%$ for milk pudding. Enterotoxin A secreting Staphylococcus aureus count in chicken Sandwich was $2 x$ $10^{8}$ CFU. $g^{-1}$. Results of the questionnaire appleied to patrons, and results of bacteriological analysis of food items, provided circunstantial evidence to conclude that an outbreak of foodbome intoxication caused by the chicken sandwich contaminated with Staphylococcus aureus enterotoxin A has ocurred.

Key words: foodbome intoxication, Staphylococcus aureus, enterotoxin A.

A intoxicação causada por alimentos contendo enterotoxinas de Staphylococcus aureus é um dos tipos mais comuns de doenças de origem alimentar em todo o mundo. Como é uma doença de curso rápido e não muito grave, os indivíduos afetados geralmente não necessitam de atendimento médico e a maioria dos casos não é notificada. Os principais sintomas desta intoxicação são vômitos e diarréia, podendo ocorrer também náuseas, cólicas abdominais e sudorese. Estes sintomas, que têm curta duração, variam com o grau de susceptibilidade do indivíduo, com a concentração da enterotoxina no alimento e a quantidade ingerida. No caso de Staphylococcus aureus, são necessárias cerca de $10^{6}$ células por grama de alimento para que a toxina seja acumulada em níveis capazes de provocar uma intoxicação. $\mathrm{O}$ período de

${ }^{1}$ Nutricionista, Mestre, Faculdade de Nutrição, Universidade Federal de Pelotas (UFPel), RS.

${ }^{2}$ Nutricionista, Mestre, aluna do Doutorado em Biotecnologia Agrícola, Cenbiot e Faculdade de Nutrição, UFPel, RS.

${ }^{3}$ Nutricionista, Faculdade de Nutrição, UFPel, RS.

${ }^{4}$ Nutricionista, Restaurante Universitário, UFPel, RS.

${ }^{5}$ Laboratorista, Faculdade de Nutrição, UFPel, RS.

${ }^{6}$ Médico Veterinário, Doutor, Professor de Epidemiologia, Centro de Zoonozes, Faculdade de Veterinária, UFPel, RS.

${ }^{7}$ Engenheiro Agrônomo, Diretor da Faculdade de Nutrição, UFPel, RS.

${ }^{8}$ Médico Veterinário, PhD, Professor de Microbiologia de Alimentos da Faculdade de Nutrição e Pesquisador do Centro de Biotecnologia, UFPel, CP 354, 96010-900, Pelotas, RS, Brasil. E-mail: biotjaga@ufpel.tche.br. Autor para correspondência. 
incubação da doença pode variar de 30 minutos até 8 horas, porém, na maioria dos casos, os sintomas aparecem entre 2 a 4 horas após a ingestão do alimento contaminado (JABLONSKY \& BOHACH, 1997). Em geral, alimentos que requerem muita manipulação durante a preparação e que, após, são mantidos em temperaturas elevadas, apresentam maior risco de causar esta intoxicação (ANONYMOUS, 2002).

Neste trabalho, são apresentados os resultados da investigação de um surto de doença de origem alimentar em um restaurante institucional em Pelotas-RS, no qual as pessoas doentes apresentaram sintomas sugestivos de uma intoxicação estafílocócica após ingerirem uma refeição composta de sanduíche de galinha, refresco de laranja e pudim de leite. Foi aplicado questionário às 88 pessoas que ingeriram a refeição contaminada para identificar aquelas que apresentaram quadro gastrintestinal, quais alimentos ingeriram, quais manifestações clínicas tiveram e o tempo transcorrido entre a ingestão da refeição e o aparecimento dos sintomas e sinais. O critério definidor de caso para este surto baseou-se na ocorrência de vômito e ou diarréia até 12 horas após a refeição.

Foram realizadas contagens de bactérias aeróbicas mesófilas, coliformes totais e fecais e de Staphylococcus aureus em amostras do sanduíche de galinha e do refresco de laranja. Adicionalmente, também foi investigada a presença de Salmonella spp. nos alimentos citados. Não houve sobras do pudim de leite para serem pesquisadas. As análises foram realizadas de acordo com as recomendações do Bacteriological Analytical Manual (FOOD AND DRUG ADMINISTRATION, 1998). A detecção de enterotoxina A em sobrenadantes do cultivo de isolados de Staphylococcus aureus foi realizada através do método imunoenzimático ELISA indireto.

O questionário aplicado aos 88 comensais revelou que 58 (64\%) apresentaram quadro clínico de intoxicação alimentar, tendo sido caracterizados como casos. Entre os indivíduos acometidos da intoxicação 38 $\%$ eram do sexo feminino, tinham idade entre 17 e 32 anos e instrução universitária. O tempo decorrido entre a ingestão dos alimentos e o início das manifestações (vômitos e,ou, diarréia) variou de uma hora e meia a 12 horas com uma mediana de três horas e meia. Outros sintomas relatados foram prostração (31 pessoas), dores abdominais ( 28 pessoas), cefaléia ( 7 pessoas) e febre ( 5 pessoas). Duas pessoas procuraram atendimento médico e todas estavam completamente recuperadas 24 a 36 horas após início dos sintomas. As taxas de ataque específico foram de $64 \%$ para o sanduíche de galinha, $61 \%$ para o refresco de laranja e $60 \%$ para o pudim.

$\mathrm{O}$ resultado da análise bacteriológica revelou contagem de Staphylococcus aureus secretores de enterotoxina A no sanduíche de galinha de $2 \times 10^{8} \mathrm{UFC} / \mathrm{g}$. (Tabela 1). Embora não se tenham dados sobre a existência de enterotoxinas de Staphylococcus aureus nos alimentos consumidos, as demais informações obtidas nesta investigação apontam para um surto de intoxicação estafílocócica produzido pelo sanduíche de galinha. Conforme tabela 1, a análise bacteriológica mostrou que o refresco de laranja possuía uma boa qualidade higiênico-sanitária, apresentando apenas uma baixa contagem de mesófílas. Já o mesmo não pode ser dito para o sanduíche de galinha, que apresentou contagens de bactérias indicadoras muita acima do aceitável para um produto alimentício pronto para consumo (BRASIL, 1997). Além do mais, os estafilococos isolados eram secretores de enterotoxina A, conforme detectado no ELISA, e estavam presentes em número geralmente encontrado em alimentos responsáveis por intoxicações estafilocócicas. Adicionalmente, o tempo de incubação, as manifestações clínicas apresentadas pelos comensais e sua duração, são característicos deste tipo de intoxicação alimentar (BERGDOLL, 1979).

Tabela 1 - Resultados da análise bacteriológica dos alimentos envolvidos no surto de intoxicação alimentar

\begin{tabular}{lcc}
\hline $\begin{array}{l}\text { Bactérias } \\
\text { pesquisadas }\end{array}$ & Refresco de laranja & $\begin{array}{c}\text { Sanduíche de } \\
\text { galinha }\end{array}$ \\
\hline $\begin{array}{l}\text { Bactérias aeróbicas } \\
\text { mesófilas }\end{array}$ & $2 \times 10 \mathrm{UFC} / \mathrm{ml}$ & $1 \times 10^{8} \mathrm{UFC} / \mathrm{g}$ \\
$\begin{array}{l}\text { Coliformes totais } \\
\text { Coliformes fecais }\end{array}$ & $<4 \mathrm{NMP} / \mathrm{ml}$ & $>1 \times 10^{6} \mathrm{NMP} / \mathrm{g}$ \\
$\begin{array}{l}\text { Staphylococcus } \\
\text { aureus* }\end{array}$ & $<10 \mathrm{UFC} / \mathrm{ml} / \mathrm{ml}$ & $>1 \times 10^{6} \mathrm{NMP} / \mathrm{g}$ \\
Salmonella spp. & ausência em $25 \mathrm{ml} 10^{8} \mathrm{UFC} / \mathrm{g}$ & ausência em $25 \mathrm{~g}$ \\
\hline
\end{tabular}

*secretores de enteroxina A segundo o teste ELISA.

\section{REFERÊNCIAS BIBLIOGRÁFICAS}

ANONYMOUS. Staphylococcus aureus. In: Foodborne pathogenic microorganisms and natural toxins (Thé Bad Bug Book). Center for Food Safety and Applied Nutrition. U. S. Food and Drug Administration. Capturado em 27 de agosto. 2002. Online. Disponível na Internet: http:// www.cfsan.fda.gov/ mow/chap3.html

BERGDOLL, M.S. Staphylococcal intoxications. In: RIEMANN, H.; BRYAN, F.L. Foodborn infections and intoxications. New York : Academic, 1979. Cap. IX. p.443494.

BRASIL. Ministério da Saúde. Secretaria Nacional de Vigilância Sanitária de Alimentos - DINAL. Padrões microbiológicos 
para produtos expostos à venda ou de alguma forma destinados ao consumo. Portaria $\mathrm{n}^{\circ} 451$, de 19 de setembro de 1997. Diário Oficial [da República Federativa do Brasil], Brasília, p.21005-21012, 22 de setembro de 1997, Seção I.

FOOD AND DRUG ADMINISTRATION. Bacteriological
Analytical Manual, 8. ed. Gaithersburg : AOAC Intemational, 1998. 581p.

JABLONSKY J.M.; BOHACH G.A. Staphylococcus aureus. In: DOYLE M.H.; BEUCHAT L.R; MONTVTLLE T. J. Food microbiology. Fundamentais and frontíers. Washington D.C.: ASM, 1997. Cap.19, p.353-375. 